\title{
Selection of Rice (Oryza sativa L.) Cultivars Tolerant to Drought Stress at the Vegetative Stage under Field Conditions
}

\author{
Sumontip Bunnag*, Prapaporn Pongthai \\ Genomics and Proteomics Research Group for Improvement of Salt-Tolerant Rice, Department of Biology, Faculty of Science, Khon \\ Kaen University, Khon Kaen, Thailand. \\ Email: ${ }^{*}$ sumbun@kku.ac.th
}

Received June $21^{\text {st }}, 2013$; revised July $21^{\text {st }}, 2013$; accepted August $4^{\text {th }}, 2013$

Copyright (C) 2013 Sumontip Bunnag, Prapaporn Pongthai. This is an open access article distributed under the Creative Commons Attribution License, which permits unrestricted use, distribution, and reproduction in any medium, provided the original work is properly cited.

\begin{abstract}
Water status is one of the critical factors affecting rice production. Rice cultivars tolerant to drought stress at the vegetative stage under field conditions were selected. Seven rice cultivars, namely, KDML 105, IR58821, CT9993, IR62266, IR57514, IR52561 and BT, were included in this study. The plant height, number of tillers per plant, leaf rolling, leaf death, leaf water potential, relative leaf water content and proline content in plants subjected to drought stress for 0,20 and 60 days were recorded. Based upon the levels of water stress tolerance, three groups of rice cultivars were recognized, as follows: highly drought-tolerant, moderately drought-tolerant and drought-sensitive cultivars. The CT9993 rice cultivar was considered to be a highly drought-tolerant cultivar. The moderately drought-tolerant cultivars included KDML 105, IR58821, IR57514, IR52561 and BT. The IR62266 cultivar was considered sensitive to drought.
\end{abstract}

Keywords: Proline; Leaf Rolling; Leaf Death; Leaf Water Potential

\section{Introduction}

Rice (Oryza sativa L.) is one of the most widely consumed cereal crops, providing a staple diet for almost half of the world's population [1]. Rice-growing areas occupy the tropics, subtropics, semiarid tropics and temperate regions of the world. More than $90 \%$ of the world's rice is grown and consumed in Asia, where rice is cultivated on 135 million ha with an annual production of 516 million tonnes [2]. In Thailand, a total of 11.116 million ha is dedicated to growing rice [3], and the northeastern and northern regions of the country are the major rice-growing areas. The predominant rice-growing areas in the two regions are often threatened by severe water deficit, partly due to low-input irrigation systems. In addition, emerging water shortages resulting from economic development and urbanization are leading to rationing of water in regions where irrigated lowland rice has traditionally been grown, and these production systems are also becoming water-limited. Accordingly, rice yield in these regions is low and fluctuates [4]. Water de-

"Corresponding author. ficit may occur early in the growing season or at any time from flowering to grain filling, and the intensity of the stress depends on the duration and frequency of the water deficit [5]. Drought stress suppresses leaf expansion, tillering and midday photosynthesis [6], and it reduces the photosynthetic rate and leaf area due to early senescence [7]. All of these factors are responsible for a reduction in grain yield under drought conditions. Furthermore, water deficit also increases the formation of reactive oxygen species (ROS), resulting in lipid peroxidation, protein denaturation and nucleic acid damage with severe consequences affecting the overall metabolism [8], thereby leading to a reduction in grain yield.

Rice is most susceptible to drought stress at both the vegetative and reproductive stages $[9,10]$. A dramatic reduction in grain yield occurs when drought stress coincides with irreversible reproductive processes [10,11]. Early-season drought occurs in most areas, affecting the timely transplanting of seedlings and the growth of direct-seeded rice. Late-season drought develops in most years at the end of the rainy season before crop maturation, particularly in paddy rice in a high toposequence 
position $[9,12]$.

The phenology, particularly at the reproductive stage, is a major determinant of grain yield in rain-fed lowland rice, and any attempt to screen for drought resistance needs to consider variation at the reproductive stage [13]. However, the vegetative stage is another critical determinant of the growth and maturation of rice. Therefore, selecting rice cultivars that confer drought resistance from different cultivars with contrasting drought tolerance at the vegetative or reproductive stages will bring new insights for the breeding of rice.

\section{Materials and Methods}

\subsection{Drought Stress Treatments and Measurements}

Seven rice cultivars, KDML 105, IR58821, CT9993, IR62266, IR57514, IR52561 and BT, were used in this study. Field experiments were conducted at the experimental farm (Muaeng district, Khonkaen province, Thailand; $102^{\circ} 49^{\prime} \mathrm{E}, 16^{\circ} 25^{\prime} \mathrm{N}$, and $152 \mathrm{~m}$ above sea level) at the Khonkaen Rice Experiment Station from December 1999 to April 2000. The experiments were conducted in a $2.20 \mathrm{~m} \times 16.40 \mathrm{~m}$ concrete box filled with local lateritic soil, and the box was located under a rainout shelter with removable roof panels. Three to four seeds of each rice cultivar were directly sown in each burrow prepared within the concrete box in $20 \mathrm{~cm}$ rows with an isolation distance of $15 \mathrm{~cm}$ from any other rice seed. After 14 days of germination, only one plantlet was left to grow in each burrow, whereas the other rice plantlets were removed. Pesticides were applied biweekly at the manufacturers' recommended rates. The plants also received fertilizers biweekly with an $\mathrm{N}-\mathrm{P}_{2} \mathrm{O}_{5}-\mathrm{K}_{2} \mathrm{O}$ ratio of $8-8-8(\mathrm{~kg} / \mathrm{rai})$, and water was drained 42 days after seed germination.

The experiments were laid out in a randomized complete block design in which each treatment was replicated three times. For comparison, a well-watered treatment was also included in the experiment as the control treatment. At the end of the drought treatment, the control and drought-stressed plants were sampled. The plant height and number of tillers per plant were measured at the beginning and end, respectively, of the drought-stress treatment. The plant height was measured from the stem base to the highest leaf tip.

A comparison of the degree of leaf rolling between the plants subjected to drought stress and those under normal irrigation during the same period was determined based on a standard chart presented by O'Toole and Cruz (1980) [14]. A visual score was assigned to indicate the degree of leaf rolling found on the sample leaf using a scale ranging from 1 to 5 , with 1 indicating the first evidence of rolling and 5 indicating a closed cylinder. The leaf death (drought score) of the plants subjected to drought stress was compared with that of the control plants under normal irrigation during the same period using standard criteria proposed by a standard evaluation system for rice [15]. A visual score was assigned for the degree of leaf death found on the sample leaf using a scale ranging from 0 to 9 , with 0 indicating no symptoms and 9 indicating apparent death.

\subsection{Measurements of Leaf Water Potential and Relative Leaf Water Content}

Leaf water potentials were measured using the pressure chamber technique described by Turner (1981) [16] by pressurizing the chamber with $\mathrm{N}$ gas until plant sap accumulated at the cut end of the leaf. The leaf water potential was determined at three intervals. The first test was performed when the 40-day-old plants were in nonstress conditions. The second leaf water potential determination was performed on 60-day-old plants subjected to drought stress for 20 days (mild stress), and the last interval test was conducted after the 100-day-old plants were subjected to drought stress for 60 days (severe stress).

The relative leaf water contents were also measured based on the method described by Turner (1981) [16]. The relative leaf water content was determined in the fully expanded leaf. The fresh weights of the sample leaves were recorded, and the leaves were immersed in distilled water in a Petri dish. After $2 \mathrm{~h}$, the leaves were removed, the surface water was blotted off, and the turgid weight was recorded. The samples were then dried in an oven at $70^{\circ} \mathrm{C}$ to constant weight. The relative leaf water content was calculated using the following formula:

$$
\operatorname{RLWC}(\%)=[(\mathrm{FW}-\mathrm{DW}) /(\mathrm{TW}-\mathrm{DW})] \times 100 ;
$$

where FW is the fresh weight; DW is the dry weight; and TW is the turgid weight.

\subsection{Determination of Proline Content}

The proline content in the leaves was estimated based on the method described by Bates et al. (1973) [17]. Briefly, $0.1 \mathrm{~g}$ of rice leaves was ground with $5 \mathrm{ml}$ of $3 \%$ sulfosalicylic acid, and the mixture was then filtered. To 2 $\mathrm{ml}$ of the filtered mixture in a test tube, $2 \mathrm{ml}$ of acidninhydrin and $2 \mathrm{ml}$ of glacial acetic acid were added. The mixture was mixed with a Vortex mixer and boiled at $100^{\circ} \mathrm{C}$ for $1 \mathrm{~h}$. The mixture was then frozen in ice and combined with $4 \mathrm{ml}$ of toluene, mixed, and then left to stand for $5-10 \mathrm{~min}$. Absorbance of the reddish pink upper phase was recorded at $520 \mathrm{~nm}$ against a toluene blank. 


\subsection{Statistical Analysis}

The physiological results were exported to the Statistical Package for Social Sciences v 17.0 software (SPSS Inc., Chicago, Illinois, USA), and analysis of variance (ANOVA) was used for statistical analysis. The means of the various results were tested for level of significance by Duncan's multiple range test (DMRT). Statistical significance was accepted at $p<0.05$.

\section{Results}

\subsection{Phenotypic Variations}

The well-watered plants showed normal growth of the stems. Under mild drought stress conditions (after 20 days of the treatment), the plants showed a slight reduc- tion in the growth rate of the stems, and the growth rate reduction became more dramatic under severe stress (after 60 days of the treatment). IR52561 showed the highest plant height with an average of $93 \mathrm{~cm}$ followed by IR58821 $(88 \mathrm{~cm})$, BT $(72 \mathrm{~cm})$ and IR62266 $(72 \mathrm{~cm})$ as presented in Figure 1(b). The plants subjected to drought stress showed a decrease in tillering rates compared with the well-watered plants. Under mild drought stress, the plants showed a slight reduction in tillering rates, and the rates became more dramatic when the plants were subject to severe drought stress. IR62266 showed the highest number of tillers per plant, at 8, and CT9993 displayed the lowest number of tillers per plant at 3 . The other cultivars showed the number of tillers per plant as 5 as shown in Figure 1(c).

Leaf rolling, which is a visible sign of drought stress,

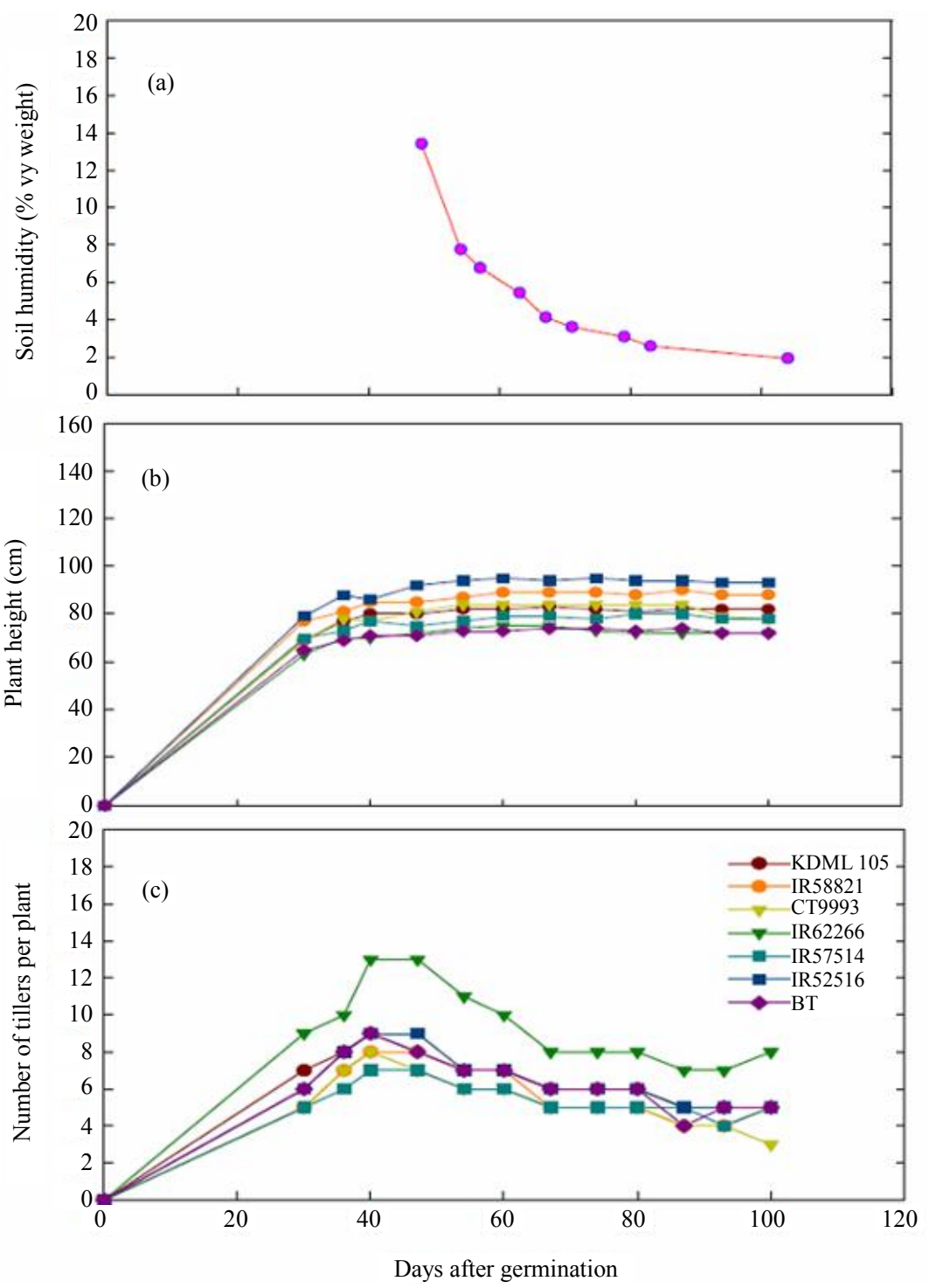

Figure 1. Soil humidity (a), plant height (b) and number of tillers per plant (c) of the seven rice cultivars subjected to drought stress. 
was observed in all the cultivars after 7 days of the drought treatment. The controls remained unrolled, but the degree of leaf rolling in all the other cultivars became progressively more pronounced with the drought stress treatment. The responses of the real rolling score to soil water stress are presented in Figure 2. After 7 days of the drought treatment, all the cultivars showed a low degree of leaf rolling (Degree 1). When the soil water became more deficient, different degrees of leaf rolling were observed among the cultivars. After 27 days of the treatment, IR62266 and IR52561 progressively developed Degree 4 of the leaf rolling symptom, and the other cultivars were at Degree 3. After 47 days of the treatment, CT9993 was found to develop Degree 4 of the leaf rolling symptom, and the other cultivars showed leaf rolling at Degree 5. Leaf death, which is another visible sign of drought stress, developed from the leaf tips and extended to all the plant parts and finally to all the tillers. After 14 days of the treatment, all the cultivars developed Degree 2 of the leaf death symptom in response to drought. Afterwards, different degrees of leaf death were found in the different cultivars. KDML 105, IR62266 and IR52561 developed the symptom more rapidly than the other cultivars under severe drought stress conditions. CT9993 showed $70 \%$ leaf death (Degree 7) after 47 days of the treatment, and the other cultivars developed leaf death symptoms at percentages greater than $70 \%$ (Degree 8). IR62266 had the highest degree of leaf death as shown in Figure 3.

\subsection{Acclimation to Water Stress: Leaf Water Potential, Relative Leaf Water Content and Proline Content}

The drought treatment of the seven rice cultivars resulted in water deficit. The responses of the flag leaves of all the cultivars towards water deficit were compared by analyzing the leaf water potential $\left(\Psi_{\mathrm{L}}\right)$ in both the daytime and nighttime. During the daytime, none of the cultivars from the controls or the plants subjected to mild drought stress showed significant differences in the $\Psi_{\mathrm{L}}$, but significant differences in the $\Psi_{\mathrm{L}}$ became more evident when the plants were subjected to severe stress (Figure 4(a)).

The $\Psi_{\mathrm{L}}$ was reduced to $-1.76,-1.88,-1.95$ and -2.66 in CT9993, BT, IR58821 and IR62266, respectively (Figure 4(a)). During the nighttime, the $\Psi_{\mathrm{L}}$ was not significantly different among all the cultivars. The $\Psi_{\mathrm{L}}$ reduced the most under severe drought stress. The $\Psi_{\mathrm{L}}$ dropped to $-0.56,-0.57$ and -1.28 in BT, CT9993 and IR62266, respectively (Figure 4(b)).

The relative leaf water content (RLWC) of all the cultivars, subjected to different drought stress conditions, was compared in both the daytime and nighttime. During the daytime, no significant differences were found in the RLWC among the cultivars prior to being subjected to drought stress with results ranging from $99.5 \%-99.8 \%$. Severe drought stress resulted in significant differences in the RLWC among the cultivars. The RLWC was reduced to $92.9,92.3$ and $86.1 \%$ in CT9993, BT and

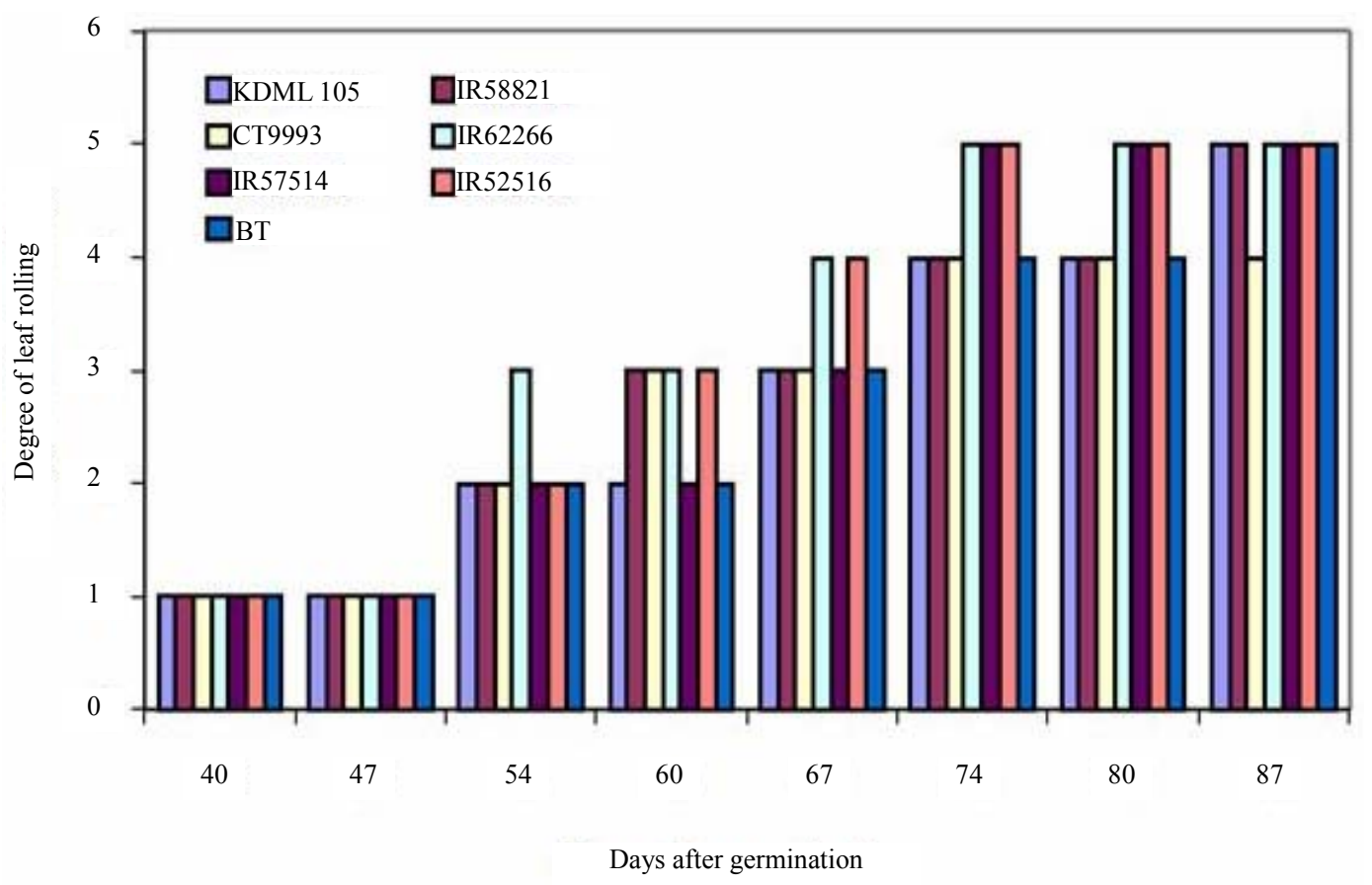

Figure 2. Degree of leaf rolling in the seven rice cultivars subjected to drought stress. 


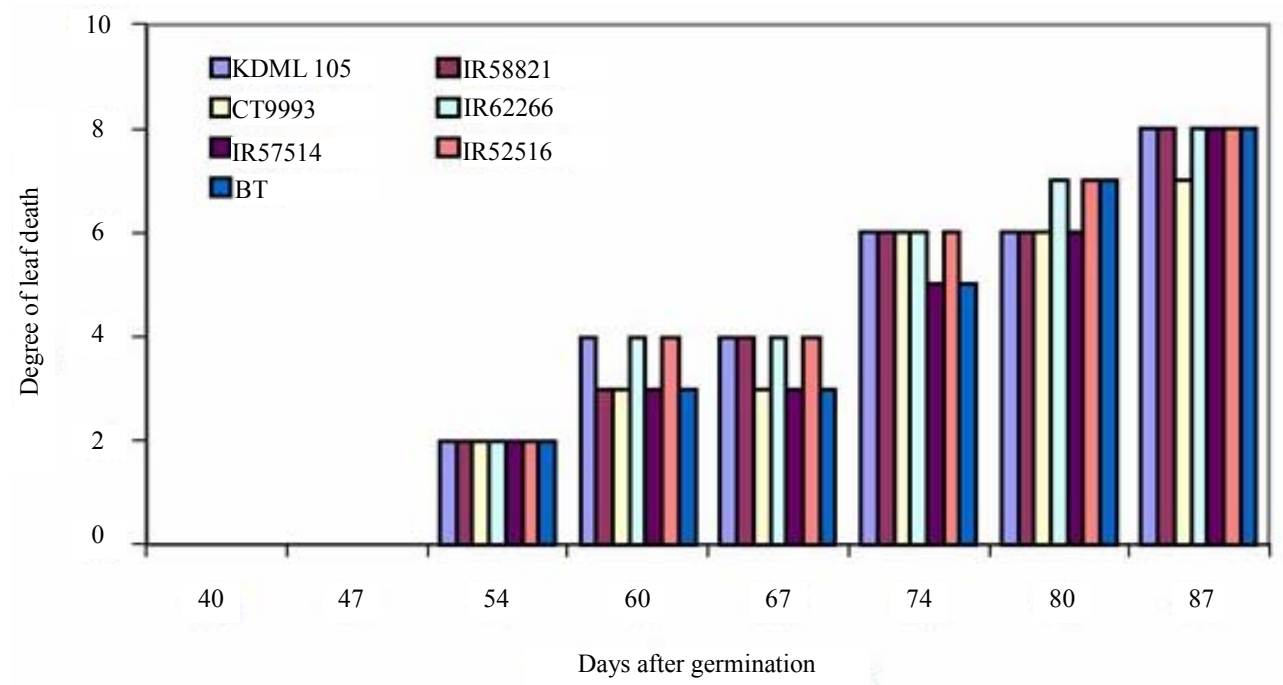

Figure 3. Degree of leaf death in the seven rice cultivars subjected to drought stress.

(a)

Days after germination

40

60 100

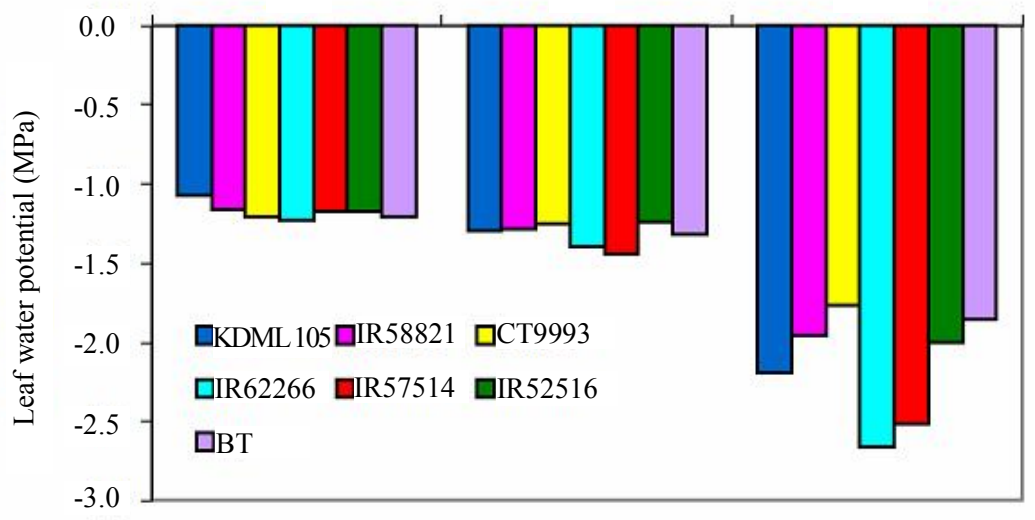

(b)

Days after germination

$40 \quad 60 \quad 100$

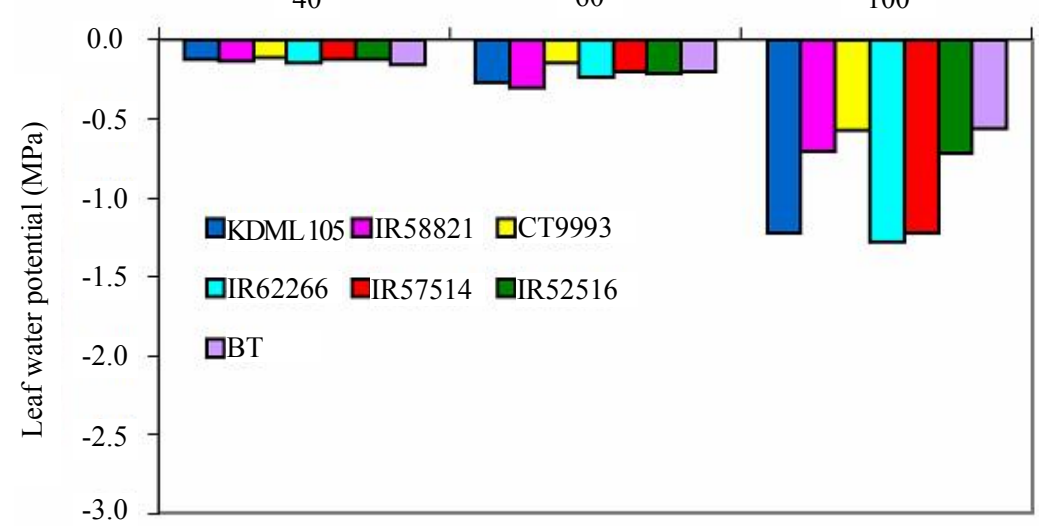

Figure 4. Leaf water potential during the daytime (a) and nighttime (b) in seven rice cultivars subjected to different drought stress conditions. 
IR62266, respectively (Figure 5(a)). During the nighttime, no significant differences in the RLWC were observed among all the cultivars under normal conditions with values ranging from $99.7 \%-99.9 \%$. Significant differences in the RLWC were found under severe drought stress conditions. The RLWC dropped to $92.7 \%$ in KDML 105, CT9993 and IR52561, and the RLWC was reduced to $99.3 \%$ in IR62266 (Figure 5(b)).

The proline contents in all the cultivars under both normal and mild drought stress conditions were significantly different. However, severe drought stress conditions produced non-significant differences among the rice cultivars. KDML 105, IR62266 and IR52561 accumulated a large amount of proline compared with the normal level of proline found in CT9993 and BT, resulting in no significant differences among the cultivars (Figure 6).

\section{Discussion}

Drought stress directly affects the growth of rice plants by reducing plant height and the number of tillers per plant because plants are unable to absorb soil water when soil water becomes inadequate, resulting in the essential elements being less available to the plants. The plant cells become less turgid, leading to a reduction in cell division and expansion. Therefore, the growth of the stems is retarded [18]. Gupta (1997) [19] found that plants subjected to drought stress have smaller-sized stomata, which results in less carbon dioxide being introduced. Furthermore, the amount of active chlorophyll is also reduced, lowering photosynthesis activity and thereby resulting in inadequate photosynthetic products for the activities within the plant cells leading to retarded growth of the plants.

Datta (1975) [20] found that rice grown under drought stress ranging from -0.7 to $-0.8 \mathrm{MPa}$ show slightly retarded height at the vegetative and flowering stages. Under drought stress ranging from -1.8 to $-1.9 \mathrm{MPa}$, dramatically reduced growth of plant height is observed.

Plants also respond to water deficit by developing the leaf rolling symptom. All the cultivars showed higher

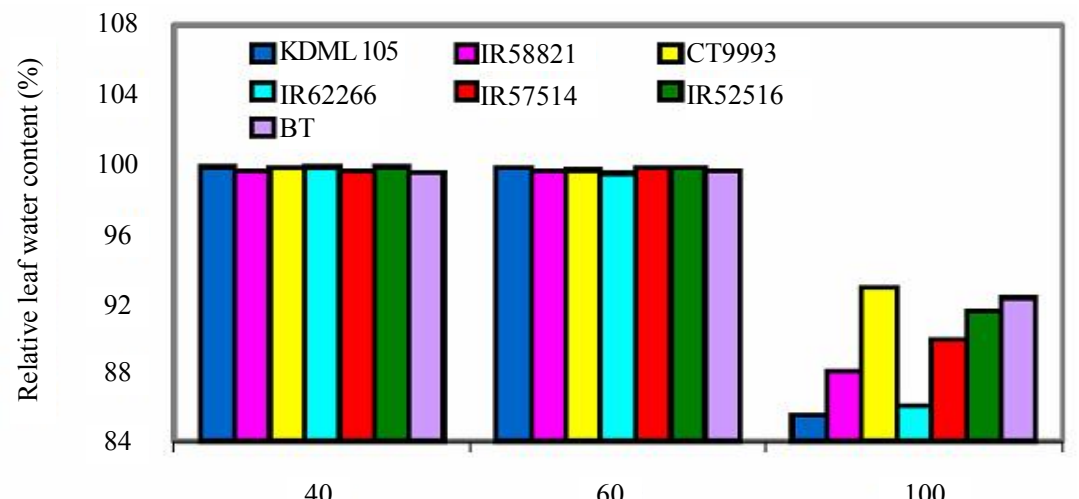

40

60

100

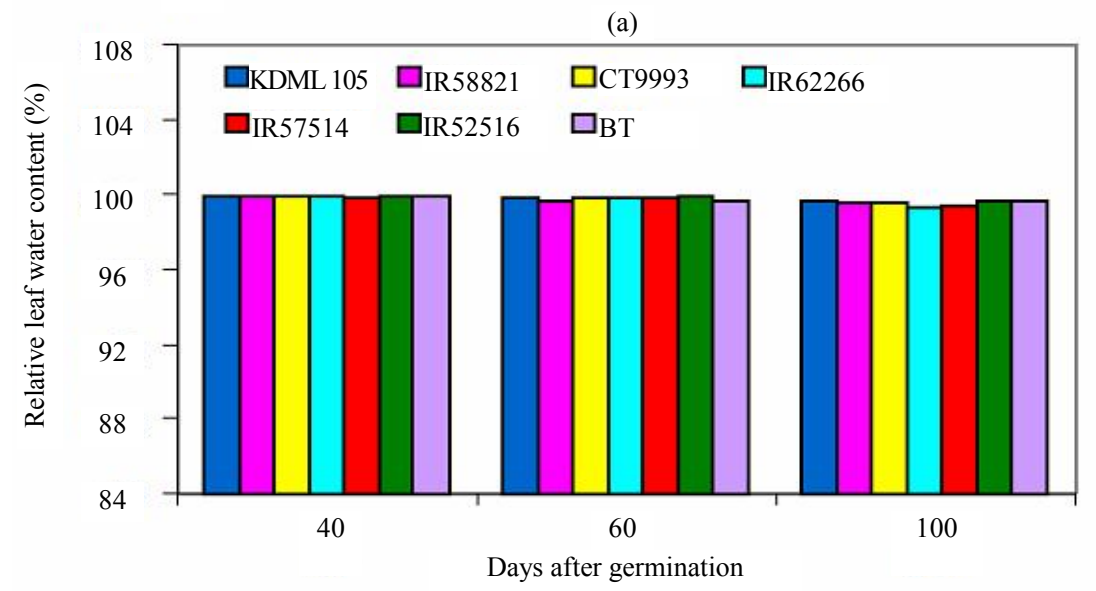

(b)

Figure 5. Relative leaf water content during the daytime (a) and nighttime (b) in seven rice cultivars subjected to drought stress. 


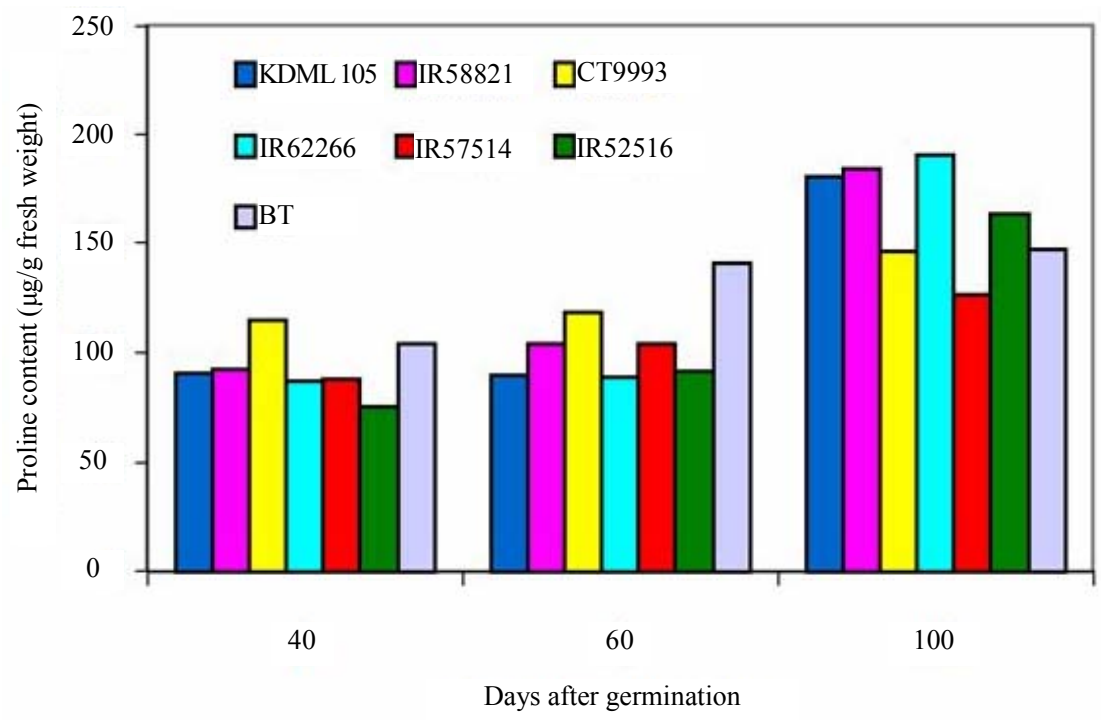

Figure 6. Proline content measured in the leaves from seven rice cultivars subjected to drought stress.

degrees of leaf rolling when the levels of water deficit were elevated. Based on the results from this study, CT9993 showed a lower degree of leaf rolling than the other cultivars. These findings were in agreement with the results of Dingkuhn et al. (1991) [21], who reported that leaf rolling is one of the mechanisms found in plants to escape drought. This mechanism can be explained by the plants adjusting their leaf water potential to allow them to absorb soil water better than other plants with low capabilities to adjust their leaf water potential under drought stress. As a result, leaf rolling is uncommon in these better-adjusting plants, so their photosynthesis was not prohibited.

Leaf death is another visible sign of drought stress that plants initially develop from the leaf tips. According to the findings obtained in this study, CT9993 showed the lowest degree of leaf death. Sigari et al. (1997) [22] reported that the degree of leaf rolling is related to leaf death. Plants with a good capacity for leaf water potential adjustment can keep their leaves expanded such that the symptoms of leaf rolling and death are not developed, suggesting that the plants can rapidly recover from drought.

Under severe drought stress, a reduction was found in the $\Psi_{\mathrm{L}}$ in all the rice cultivars. Based on the present study, CT9993 was the only cultivar that was able to maintain its leaf water potential. Munns (2002) [23] reported that a reduction in leaf water potential occurs when soil water becomes deficient, resulting in the plants being less able to absorb water and leading to a decrease in turgidity and leaf water potential. The RLWC is another parameter to determine the ability of plants to withstand drought. The present study indicated that various cultivars can resist drought differently. Nguyen et al. (1997) [24] stated that drought-tolerant cultivars can maintain the water status in their leaves, which demonstrates their ability to cope with drought stress.

Accumulation of proline in plants is a result of drought stress. In the present study, plants tended to increasingly accumulate proline under severe drought stress.

\section{Conclusion}

In summary, the studied rice cultivars displayed different abilities to resist drought. Based on the present study, the rice cultivars could be classified into 3 categories based on their responses to drought. CT9993 was a highly drought-tolerant cultivar. KDML 105, IR58821, IR57514, IR52561 and BT were considered to be moderately drought-tolerant cultivars, and IR62266 was considered to be sensitive to drought.

\section{Acknowledgements}

This work was financially supported by the Graduate School of Khon Kaen University, Thailand. The authors thank to KKU Publication Clinic for providing professional editing service from American Journal Experts. We are indebted to the Department of Biology of the Faculty of Science of Khon Kaen University for granting us permission to use the devices necessary for the study.

\section{REFERENCES}

[1] Z. P. Song, B. R. Lu, Y. G. Zhung and J. K. Chen, "Gene Flow from Cultivated Rice to the Wild Species Oryza rufipogon under Experimental Field Conditions," New Phytologist, Vol. 157, No. 3, 2003, pp. 657-665. doi:10.1046/j.1469-8137.2003.00699.x 
[2] R. N. Roy and R. V. Misra, "Economic and Environmental Impact of Improved Nitrogen Management in Asian Rice-Farming Systems," Proceedings of the 20th Session of the International Rice Commission, 2002, pp. 23-26.

[3] OAE (Office of Agricultural Economics), "Report on Survey of Rice Growing Areas in Thailand Crop Year 2012/2013," Center for Agricultural Information, Office of Agricultural Economics, Ministry of Agriculture and Cooperation, Bangkok, 2013.

[4] B. Jongdee, "Designing a National Breeding Program for Developing Drought-Tolerant Rainfed Lowland Varieties: The Thailand Experience," In: K. S. Fischer, R. Lafitte, S. Fukai, G. Atlin and B. Hardy, Eds., Breeding Rice for Drought-Prone Environments 64-69, International Rice Research Institute, Los Banõs, The Philippines, 2003.

[5] L. J. Wade, C. G. McLaren, L. Quintana, D. Harnpichitvitaya, S. Rajatasereekul, A. K. Sarawgi, A. Kuma, H. U. Ahmed, A. K. Sarwoto, R. Singh, J. Rodriguez, Siopongco and S. Sarkarung, "Genotype by Environment Interactions across Diverse Rainfed Lowland Rice Environments," Field Crops Research, Vol. 64, No. 1, 1999, pp. 35-50. doi:10.1016/S0378-4290(99)00049-0

[6] P. J. Kramer and J. S. Boyer, "Water Relations of Plant and Soil," Academic Press, San Diego, 1995.

[7] L. D. Nooden, "The Phenomena of Senescence and Aging," In: L. D. Nooden and A. C. Leopald, Eds., Senescence and Aging in Plants, Academic Press, San Diego, 1988, pp. 1-50.

[8] J. M. Hansen, Y. M. Go and D. P. Jones, "Nuclear and Mitochondrial Compartmentation of Oxidative Stress and Redox Signaling," Annual Review of Pharmacology and Toxicology, Vol. 46, 2006, pp. 215-34. doi:10.1146/annurev.pharmtox.46.120604.141122

[9] B. Jongdee, "New Rice Breeding Methods for Rainfed Lowlands of North and Northeast Thailand," Proceedings of an International Workshop: Increased Lowland Rice Production in the Mekong Region, Vientiane, 30 October-2 November 2000, pp. 221-228.

[10] G. Pantuwan, S. Fukai, M. Cooper, S. Rajatasereekul and J. C. O'Toole, "Yield Response of Rice (Oryza sativa L.) Genotypes to Drought under Rainfed Lowlands 2. Selection of Drought Resistant Genotypes," Field Crops Research, Vol. 73, No. 2-3, 2002, pp. 169-180. doi:10.1016/S0378-4290(01)00195-2

[11] A. Price and B. Courtois, "Mapping QTLs Associated with Drought Resistance in Rice: Progress, Problems and Prospects," Plant Growth Regulation, Vol. 29, 1999, pp. 123-133. doi:10.1023/A:1006255832479

[12] B. Jongdee, "Designing a National Breeding Program for Developing Drought Tolerant Rainfed Lowland Varieties: The Thailand Experiences," In: K. S. Fischer, R. Lafitte, S. Fukai, G. Atlin and B. Hardy, Eds., Breeding Rice for
Drought-Prone Environments, International Rice Research Institute, Los Banõs, 2004. pp. 64-69.

[13] G. Pantuwan, S. Fukai, M. Cooper, S. Rajatasereekul and J. C. O'Toole, "Yield Response of Rice (Oryza sativa L.) Genotypes to Drought under Rainfed Lowlands. 1. Grain Yield and Yield Components," Field Crop Research, Vol. 73, 2001, pp. 153-168. doi:10.1016/S0378-4290(01)00187-3

[14] J. C. O'Toole and R. Cruz, "Response of Leaf Water Potential, Stomatal Resistance and Leaf Rolling to Water Stress," Plant Physiology, Vol. 65, No. 3, 1980, pp. 428432. doi: $10.1104 /$ pp.65.3.428

[15] IRRI, “Annual Report for 1975,” International Rice Research Institute, Los Banõs, 1976, p. 418.

[16] N. C. Turner, "Techniques and Experimental Approaches for the Measurement of Plant Water Status," Plant Soil, Vol. 58, No. 1, 1981, pp. 339-366. doi:10.1007/BF02180062

[17] L. S. Bates, R. P. Waldren and I. D. Teare, "Rapid Determination of Free Proline for Water Stress Studies," Plant and Soil, Vol. 39, No. 1, 1973, pp. 205-208. doi:10.1007/BF00018060

[18] T. C. Hsiao, J. C. O'Toole, E. B. Yambao and N. C. Turner, "Influence of Osmotic Adjustment on Leaf Rolling and Tissue Death in Rice (Oryza sativa L.)," Plant Physiology, Vol. 75, No. 1, 1984, pp. 338-341. doi: $10.1104 /$ pp. 75.2 .338

[19] U. S. Gupta, "Crop Improvement: Stress Tolerance," Science Publishers, Inc., New Hamphire, 1997.

[20] S. K. Datta, "Drought Tolerance in Rice in Relation to Growth Stages," IRRI, Los Banõs, 1975.

[21] M. Dingkuhn, R. T. Cruz, C. O. O’Toole, N. C. Turner and K. Doerffling, "Responses of Seven Diverse Rice Cultivars to Water Deficits. III. Accumulation of Abscisic Acid and Proline in Relation to Leaf Water Potential and Osmotic Adjustment," Field Crops Research, Vol. 27, No. $1-2,1991$, pp. 103-117. doi:10.1016/0378-4290(91)90025-Q

[22] A. Sigari, L. J. Wadel and A. Yamauch, "Response of Roots Traits of Rainfed Lowland Rice to Drought and Rewatering," In: J. Abe and S. Morita, Eds., Root System Management that Leads to Maximize Rice Yields, JSRR, Tokyo, 1997.

[23] R. Munns, "Comparative Physiology of Salt and Water Stress," Plant, Cell and Environment, Vol. 25, No. 2, 2002, pp. 239-250. doi:10.1046/j.0016-8025.2001.00808.x

[24] H. T. Nguyen, R. C. Babu and A Blum, "Breeding for Drought Resistance in Rice: Physiology and Molecular Genetics Considerations," Crop Science, Vol. 37, No. 5 , 1997, pp. 1426-1434. doi:10.2135/cropsci1997.0011183X003700050002x 